\title{
Providing nomadic people with health care
}

\author{
The Kenyan government and medical charities \\ are fighting hard to deliver good health care to \\ the people of Kenya. Deborah Cohen looks at \\ the particular difficulties involved in providing \\ care to the nomadic people of Turkana, in the \\ north west of the country
}

Tuberculosis is killing half a million people a year in Africa, and the World Health Organization has declared the situation an emergency. Tackling the disease in settled communities is hard enough because of the long period of treatment needed. For nomadic people, delivering the treatment poses even greater problems.

One charity that has been trying to deliver treatment is Merlin. This medical charity was founded in 1993 and specialises in medical relief and health care. The followup of patients with a nomadic lifestyle, such as the Turkana people, has always challenged Kenyan doctors, says Malweyi Inwani, Merlin's emergency medical coordinator in Kenya. DOTS (directly observed treatment short course), the preferred method of delivering treatment, is difficult to maintain. Patients start treatment

only to abandon it when the community moves to a different area.

The Turkana are nomadic pastoralists in northwest Kenya, who raise livestock for milk, meat, and blood for nourishment. They need pasture and water for their livestock and move to the most abundant sources, depending on the season. The number of people attending one of the African Medical and Research Foundation's mobile units decreases every August as people retreat into the hills for pasture and water, the foundation's survey found in 1992.

To target nomadic groups, Kenya's national leprosy and tuberculosis programme introduced the "manyatta" approach. Manyattas, traditional Kenyan huts attached to hospitals, are centres at which patients receive four months of intensive treatment for tuberculosis under con-

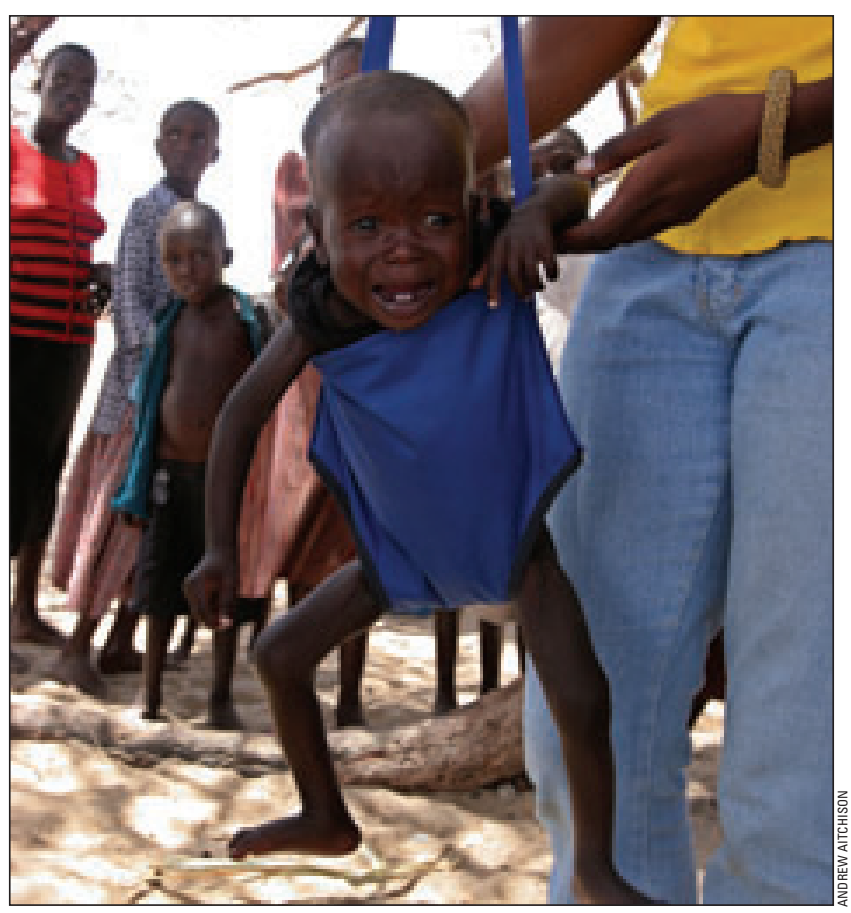

Merlin outreach workers weigh a child to check for malnutrition in Longech, Turkana stant medical supervision. More drugs are given packed so that patients can leave.

Kenyan government policy and World Health Organization directives say that treatment should be free. But the rise in tuberculosis has strained the government's treatment budget and hospitals are struggling to provide treatment free of charge. Some hospital management boards have introduced limited cost sharing for tuberculosis drugs. But the introduction of charges threatens the treatment and control of tuberculosis, thinks Dr Inwani.

Vaccination programmes and therapeutic feeding schemes have also had to adapt to the Turkana's pastoral life. Immunisations for measles have risen from $40 \%$ to $78 \%$ in the regions where Merlin operates, an internal audit shows. The charity initially piggybacked food distribution by Oxfam to supply vaccines after the 1994 drought. Now Merlin's team drives to visit distant villages to give vaccinations. Nevertheless, as mobile communities move, some children are lost to follow-up.

The rate of malnutrition is high; specialist feeding is needed to treat moderately and severely malnourished children. Therapeutic feeding centres are attached to dispensaries in larger settlements. Children with a height to weight ratio of less than $80 \%$ of the median receive fortified dry skimmed milk products from different organisations.

But as for DOTS schemes, the centres have their problems fitting around the Turkana lifestyle. According to Isaac Ekeru, field project officer for Merlin, mothers sometimes need considerable persuasion to leave other children to bring their seriously undernourished offspring to the centres. Admission undermines economic productivity and food security, prompting charities to introduce the use of home based care with ready to use therapeutic food. Children receive Plumpy Nut, brown sweetened peanut paste, as outpatients if there are no medical complications. Acute malnutrition in children was 35\% last year in Northern Turkana, and rates fell this year to $22 \%$ after interventions, an Oxfam internal survey found.

Turkana District covers 77000 $\mathrm{km}^{2}$ of the rift valley in northwest Kenya. Not only does the Turkana's lifestyle provide a challenge for health care, but the region's poor roads and bridges also hamper healthcare delivery. Paved roads are rare. Access to larger settlements away from main roads, across lakes and riverbeds, dictates four wheel drive vehicles. It's bumpy and slow in the dry season and almost impassable in the wet season.

Inadequate infrastructure increases the time and money spent on delivering health and development programmes. In larger settled communities, the Ministry of Health provides a nurse, a dispensary, and a health centre. Nurses are the backbone of health care-they carry out the duties of doctors, pharmacists, and midwives-and the broad training in the nursing college in Lodwar, the district's capital, reflects this.

Many patients or their families, nevertheless, have to walk more than $30 \mathrm{~km}$ to reach a nurse or walk to the main tarred road to hitch a lift to the nearest hospital. Most of Turkana is without a telephone or mobile telephone network. Asked if there was one thing that would make his job easier, John Ateyo, a Ministry of Health nurse, replied, "A radio."

To help people cope with their health needs away from hospital, Merlin and Oxfam train village patient helpers and traditional birthing helpers. They focus on recognising illness, referring patients when necessary, and improving sanitation and hygiene. Leah Nachere, who helps in traditional birthing and is town councillor in Kaikor, pointed out the bins-holes in the ground-and draining racks in the village. "We've had training in the importance of showering and washing clothes and utensils and drying them. We've also been told to boil water before we drink it," she said. But she added that one day's training was not enough: "People need to be monitored and have reminder training."

Although some health messages are filtering through, a concrete solution doesn't always materialise. Financial constraints mean that communities are asked by non-governmental organisations to prioritise their needs. Well versed in the hygienic benefits of using latrines, several village leaders pleaded for help to build them. "We really need the equipment to build pit latrines here," said Moses Lopeyok, the chief of Longech. "The ground simply doesn't support hand dug pit latrines-it collapses." Deborah Cohen BMJ 